\title{
National coverage of reflex cryptococcal antigen screening: A milestone achievement in the care of persons with advanced HIV disease
}

HIV/AIDS-related mortality accounts for almost one-third of deaths in South Africa (SA), and globally $~ 15 \%$ of AIDS-related mortality is associated with cryptococcal disease. ${ }^{[1,2]}$ The burden of cryptococcal meningitis has remained high in SA among severely immunosuppressed HIV-positive patients, despite substantial improvements in antiretroviral treatment (ART) coverage over the past decade. ${ }^{[3]}$ Approximately one-third of patients entering HIV care in the SA public sector in 2016 had advanced HIV disease (defined as a CD4+ T-lymphocyte count $<200$ cells $/ \mu \mathrm{L}$ ), and $17 \%$ had a CD4+ count $<100$ cells $/ \mu \mathrm{L}^{[4]}$ In 2011 , the World Health Organization (WHO) recommended that countries consider integrating cryptococcal antigen (CrAg) screening into HIV programmes to detect cryptococcal disease at an earlier point in its trajectory, followed by pre-emptive antifungal treatment to reduce AIDS deaths. ${ }^{[5]}$ The CrAg screen-and-treat intervention therefore aligns with the Joint United Nations Programme on HIV/AIDS (UNAIDS) over-arching goal to reduce global AIDS deaths to $>500000$ by 2020, and has been included in a new WHO-recommended package of care for managing advanced HIV disease. ${ }^{[6]}$ Since it was first included in SA's national strategic plan for HIV/AIDS, tuberculosis and STIs in 2012, evidence has mounted in favour of the CrAg screen-andtreat intervention. A randomised controlled trial from Zambia and Tanzania revealed that pre-ART CrAg screening with pre-emptive antifungal treatment for patients with a CD $4+$ count $<200$ cells $/ \mu \mathrm{L}$, coupled with 4 weeks of community-based ART adherence support, resulted in a $28 \%$ reduction in all-cause mortality at 12 months. ${ }^{[7]}$

In the light of these data, on 1 October 2016 the National Health Laboratory Service (NHLS) implemented a ground-breaking service to provide the world's first and largest national laboratory-based $\mathrm{CrAg}$ screening programme aimed at detecting early cryptococcal disease before progression to meningitis in all HIV-seropositive patients with a CD4+ count $<100$ cells/ $\mu \mathrm{L}$ across SA. The launch of the programme was the culmination of a long, successful, nationally co-ordinated effort by the National Institute for Communicable Diseases (NICD), the National Department of Health (NDoH), the NHLS and other local and international partners.

Several activities preceded this important milestone. Following a circular (circular no. H116/2012) from the Western Cape provincial government to screen all patients whose CD4+ count was $<100$ cells/ $\mu \mathrm{L}$, a provider-initiated CrAg screening initiative was implemented in the Western Cape in mid-2012. No clinical training was offered, and no feedback was provided to clinicians in terms of the proportion of eligible patients screened at their clinics. A retrospective evaluation showed that just over a quarter of eligible patients were screened under this initiative; compared with those who were screened, those who were not screened were almost twice as likely to develop disseminated cryptococcal disease. ${ }^{[8]}$ In contrast, a simpler laboratory-based approach using remnant $\mathrm{CD} 4+$ samples reflexively tested for $\mathrm{CrAg}$ if the CD4+ count was $<100$ cells/ $\mu \mathrm{L}$ was simultaneously piloted in four districts in Gauteng and Free State provinces from 2012 through to $2015 .^{[9,10]}$ This initiative was paired with intensive clinician training on how to appropriately manage CrAg-positive patients identified through reflexed testing. In this scenario, almost $100 \%$ of eligible patients were screened for cryptococcal antigenaemia.

Implementation of these two contrasting approaches offered a valuable opportunity for parallel evaluation. A detailed costeffectiveness model demonstrated that laboratory-based reflex $\mathrm{CrAg}$ screening was simpler and more cost-effective than a clinicianinitiated approach, allowed for almost universal screening coverage, and potentially saved more lives. ${ }^{[11]}$ In 2014, the NDoH adopted a detailed screen-and-treat clinical algorithm for seamless integration into the HIV care cascade. This algorithm has subsequently been included in the Standard Treatment Guidelines/Essential Medicines List at all healthcare levels. ${ }^{[12,13]}$ Several skills-based training workshops for management of cryptococcal disease were developed and cascaded downwards to healthcare workers at facility level. On the NHLS side, the initiative facilitated the evaluation of several CrAg assays and workflow analyses for scaling up state laboratory services. ${ }^{[14-17]}$ The NHLS also undertook intensive training of laboratory personnel based on standard operating procedures and on-site assessment of laboratory work flow, enabling integration into existing CD4+ services. The development of a national laboratory proficiency testing scheme (PTS) by the NICD/NHLS completed the final phase of service delivery implementation; the first batch of PTS samples was distributed to NHLS CD4+ laboratories in November 2016. On the NDoH side, a public health planning and resource allocation exercise was conducted, specifically to ensure that fluconazole was procured and made available at all healthcare levels.

A laboratory dashboard for $\mathrm{CrAg}$ has been integrated into a broader SA HIV programme dashboard, with two key indicators: CrAg screening coverage and prevalence of cryptococcal antigenaemia. Good linkage to laboratory CrAg results is the cornerstone of this programme. Several methods are being implemented to ensure that CrAg-positive patients return for clinical evaluation and begin appropriate antifungal treatment. Weekly CrAg results for action (RFA) reports are emailed to registered end-users (currently including district/facility managers or registered healthcare workers at 220 facilities in 32 districts). RFA reports are formatted as line-lists of patients with a positive CrAg result who need urgent follow-up.

Looking ahead, the impact of the CrAg screen-and-treat programme on patient outcomes will be evaluated by clinic-based field surveys over the next 5 years through the NICD's CAST-NET project. Several interventions will also be explored to optimise implementation of CrAg screen-and-treat, including intensive refresher healthcare worker training with novel methods of delivery, patient education, enhanced delivery of laboratory results to clinicians, and risk stratification of patients by piloting semi-quantitative $\mathrm{CrAg}$ testing on reflexively tested blood specimens. ${ }^{[18]}$

Through this national CrAg screening initiative, 276125 patients were screened during the first year (October 2016 through to September 2017) with 95\% coverage, and 15757 (5.7\%) were identified with cryptococcal antigenaemia, ${ }^{[19-21]}$ highlighting both the large burden of advanced HIV disease and opportunistic infections in SA and the urgent need to recruit these very ill patients into care.

Acknowledgements. We acknowledge NHLS personnel and National Priority Programme co-ordinator Dr L M Coetzee who graciously took on the $\mathrm{CrAg}$ screening workload to enable this programme to be rolled out within the existing state $\mathrm{CD} 4+$ service, reducing implementation costs. Our group is also grateful for the important groundwork that was laid for this programme and the support received from our collaborators, funders and the NDoH. Pilot work for the CrAg screen-and-treat programme was supported by a Centers for Disease Control and Prevention (CDC) 
and NHLS co-operative agreement (CDC-RFA-GH15-1575; project PI, NPG). NPG is partially supported by the National Institute of Allergy and Infectious Diseases of the National Institutes of Health (NIH) under award no. R01AI118511. The content is solely the responsibility of the authors and does not necessarily represent the official views of the NIH or the CDC.

\section{Nelesh P Govender}

National Institute for Communicable Diseases (Centre for HealthcareAssociated Infections, Antimicrobial Resistance and Mycoses), a Division of the National Health Laboratory Service and School of Pathology, Faculty of Health Sciences, University of the Witwatersrand, Johannesburg, South Africa neleshg@nicd.ac.za

\section{Deborah K Glencross}

National Priority Programme Unit, National Health Laboratory Service and School of Pathology, Faculty of Health Sciences, University of the Witwatersrand, Johannesburg, South Africa

1. Pillay-van Wyk V, Msemburi W, Laubscher R, et al. Mortality trends and differentials in South Africa from 1997 to 2012: Second National Burden of Disease Study. Lancet Glob Health 2016;4(9):e642-e653. https://doi.org/10.1016/S2214-109X(16)30113-9

2. Rajasingham R, Smith RM, Park BJ, et al. Global burden of disease of HIV-associated cryptococcal meningitis: An updated analysis. Lancet Infect Dis 2017;17(8):873-881. https://doi.org/10.1016/S1473meningitis: An up
3099(17) 30243-8

3. Britz E, Perovic O, von Mollendorf C, et al. The epidemiology of meningitis among adults in a South African province with a high HIV prevalence, 2009 - 2012. PLoS One 2016;11(9):e0163036. https://doi. org/10.1371/journal.pone.0163036

4. Carmona S, Bor J, Nattey C, et al. Persistent high burden of advanced HIV disease among patients seeking care in South Africa's national HIV programme: Data from a nationwide laboratory cohor Clin Infect Dis 2018;66(Suppl 2):S111-S117. https://doi.org/10.1093/cid/ciy045

5. World Health Organization. Rapid Advice: Diagnosis, Prevention and Management of Cryptococcal Disease in HIV-infected Adults, Adolescents and Children. Geneva: WHO, 2011. www.who.int/hiv/ pub/cryptococcal_disease2011/en/ (accessed 3 January 2018).

6. World Health Organization. Guidelines for Managing Advanced HIV Disease and Rapid Initiation of Antiretroviral Therapy. Geneva: WHO, 2017. www.who.int/hiv/pub/guidelines/advanced-HIVdisease/en/ (accessed 3 January 2018).

7. Mfinanga S, Chanda D, Kivuyo SL, et al. Cryptococcal meningitis screening and community-based early adherence support in people with advanced HIV infection starting antiretroviral therapy in early adherence support in people with advanced HIV infection starting antiretroviral therapy in
Tanzania and Zambia: An open-label, randomised controlled trial. Lancet 2015;385(9983):2173-2182. Tanzania and Zambia: An open-label, randomised
https://doi.org/10.1016/S0140-6736(15)60164-7
8. Vallabhaneni S, Longley N, Smith M, et al. Evaluation of a public-sector, provider-initiated cryptococcal antigen screening and treatment program, Western Cape, South Africa. J Acquir Immune cryptococcal antigen screening and treatment program, Western Cape, South Africa.

9. Govender NP, Chetty V, Roy M, et al. Phased implementation of screening for cryptococcal disease in 9. Govender NP, Chetty V, Roy M, et al. Phased implementation of screening for crypto
South Africa. S Afr Med J 2012;102(12):914-917. https://doi.org/10.7196/SAMJ.6228

10. Govender NP, Chetty V, Spencer D, et al. Cryptococcal screen-and-treat in Gauteng Province, South . Govender NP, Chetty V, Spencer D, et al. Cryptococcal screen-and-treat in Gauteng Province, South
Africa: Update from the first 2 years of implementation, 2012 - 2014. S Afr J HIV Med 2014;15(4):156159. https://doi.org/10.7196/SAJHIVMED.1124

11. Larson BA, Rockers PC, Bonawitz R, et al. Screening HIV-infected patients with low CD4 counts for cryptococcal antigenemia prior to initiation of antiretroviral therapy: Cost effectiveness of alternative screening strategies in South Africa. PLoS One 2016;11(7):24. https://doi.org/10.1371/journal. pone. 0158986

12. Govender NP, Meintjes G, Bicanic T, et al. Guideline for prevention, diagnosis and management of cryptococcal meningitis among HIV-infected persons: 2013 update. S Afr J HIV Med 2013;14(2):7686. https://doi.org/10.7196/SAJHIVMED.930

13. National Department of Health, South Africa. Essential Drugs Programme: Primary Healthcare Standard Treatment Guidelines and Essential Medicines List. 5th ed. Pretoria: NDoH, 2014. www. health.gov.za/index.php/component/phocadownload/category/285-phc (accessed 13 February 2018).

14. Coetzee LM, Cassim N, Glencross DK. Laboratory diagnosis of early cryptococcal antigenaemia Coetzee LM, Cassim N, Glencross DK. Laboratory diagnosis of early cryptococcal antigenaemia
detection. Presented at the 2nd African Society for Laboratory Medicine Conference, Cape Town detection. Presented at the 2nd African Society for Laboratory Medicine Conference, Cape Town
International Convention Centre, Cape Town, South Africa, 30 November - 4 December 2014. http:// International Convention Centre, Cape Town, South Africa, 30 Noven
aslm2014.org/programme/conference-books/ (accessed 8 June 2018).

15. Coetzee LM, Cassim N, Moodley K, Glencross D. Roadmap for implementing a national early detection programme for reflexed CrAg screening in national health $\mathrm{CD} 4$ laboratories in South Africa. Presented at the 7th SA AIDS Conference, International Conference Centre, Durban, South Africa, 9 - 12 June 2014

16. Cassim N, Schnippel K, Coetzee LM, Glencross DK. Establishing a cost-per-result of laboratory-based, reflex cryptococcal antigenaemia screening (CrAg) in HIV+ patients with CD4 counts less than 100 cells $/ \mu$ using a lateral flow assay (LFA) at a typical busy CD4 laboratory in South Africa. PLoS One 2017;12(2):e0171675. https://doi.org/10.1371/journal.pone.0171675

17. Cassim N, Schnippel K, Coetzee LM, Glencross DK. Estimating the cost-per-result of a national reflexed cryptococcal antigenaemia screening program: Forecasting the impact of potential HIV guideline changes and treatment goals. PLoS One 2017;12(8):e0182154. https://doi.org/10.1371/ journal.pone.0182154

18. Wake RM, Britz E, Sriruttan C, et al. High cryptococcal antigen titers in blood are predictive of subclinical cryptococcal meningitis among HIV-infected patients. Clin Infect Dis 2017;66(5):686-692. https://doi.org/10.1093/cid/cix872

19. Coetzee LM, Cassim N, Sriruttan C, Govender NP, Glencross DK. Cryptococcal prevalence rates in patients with CD4 counts $<100$ cells $/ \mu \mathrm{l}$ in a national screening programme identifies advanced disease burden in districts for intensified programmatic support and fast tracking of patients into care. PLoS One 2018;13(6):e0198993. https://doi.org/10.1371/journal.pone.0198993

20. Coetzee LM, Cassim N, Glencross DK. Analysis of HIV disease burden by calculating the percentages of patients with CD4 counts $<100$ cells/ $\mu \mathrm{L}$ across 52 districts reveals hot spots for intensified commitment to programmatic support. S Afr Med J 2017;107(6):507-513. https://doi.org/10.7196/ SAMJ.2017.v107i6.1131

21. Coetzee LM, Cassim N, Govender NP, Glencross D. CrAg positivity rates reported from a national CD4 reflexed screening programme identify high-risk regions of co-existent HIV/cryptococcal disease, requiring urgent programmatic focus into care. Presented at the XXII International AIDS Conference, Le Palais des Congres de Paris, Paris, France, 23 - 26 July 2017. https://wwwias2017.org/ (accessed 8 June 2018).

S Afr Med J 2018;108(7):534-535. DOI:10.7196/SAMJ.2018.v108i7.13094 